\title{
SOCIO-ECONOMIC DEVELOPMENT OF THE CENTRAL FEDERAL DISTRICT OF RUSSIAN FEDERATION WITH METHODOLOGICAL ASPECTS OF INNOVATION WASTE MANAGEMENT
}

\author{
СОЦИАЛЬНО-ЭКОНОМИЧЕСКОЕ РАЗВИТИЕ ЦЕНТРАЛЬНОГО ФЕДЕРАЛЬНОГО \\ ОКРУГА РОССИЙСКОЙ ФЕДЕРАЦИИ С УЧЕТОМ МЕТОДОЛОГИЧЕСКИХ АСПЕКТОВ \\ ИННОВАЦИОННОГО УПРАВЛЕНИЯ ОТХОДАМИ
}

\author{
L.A. Shilova, Post-graduate Student \\ Л.А. Шилова, аспирант
}

\begin{abstract}
National Research University - Moscow State University of Civil Engineering, Moscow, Russia Национальный исследовательский университет - МГСУ, Москва, Россия

Phone: +7 (495) 287-49-19, E-mail: shilova_lyubov@mail.ru
\end{abstract}

Received June 29, 2012

\begin{abstract}
The author proposed a method to improve the mechanism for assessing the ecological safety of territories with regional geo-environmental tensions, social and environmental performance. The necessity to assess the re-use of material and natural resources and to provide business entities right to change the fees for environmental pollution by industrial wastes, if they are re-used in different industries.

\section{АННОТАЦИЯ}

Автором предложена методика совершенствования механизма оченки экологической безопасности территорий с учетом региональной геоэкологической напряженности, социальных и экологических показателей. Отмечена необходимость оценки степени вторичного использования материальных и природных ресурсов и предоставления субъектам предпринимательской деятельности права изменения размеров платежей за загрязнение окружающей среды промышленными отходами в случаях их повторного использования в различных отраслях народного хозяйства.
\end{abstract}

\section{KEY WORDS}

Sustainable development; Production waste; Recycling; Evaluation methodology; Methodology.

\section{КЛЮЧЕВЫЕ СЛОВА}

Устойчивое развитие; Отходы производства; Вторичное использование; Методика оченки; Методология.

Центральный федеральный округ состоит из 18 субъектов РФ: (Белгородская, Брянская, Владимирская, Воронежская, Ивановская, Калужская, Костромская, Курская, Липецкая, Московская, Орловская, Рязанская, Смоленская, Тамбовская, Тверская, Тульская и Ярославская области, а также г. Москва) и занимает площадь в 650,2 тыс. кв. км, что составляет 3,8\% территории Российской Федерации.

В наименьшей степени округ обладает простыми ресурсами, так например, на одного жителя приходится лишь 0,8 га сельхозугодий (порядка 1,5 га - среднероссийское значение), приблизительно 3000 куб. м пресной воды в год и всего 0,6 га леса (что в 10 раз меньше, чем по стране.) На территории округа разве- дано более 10,5 тыс. месторождений 38 видов полезных ископаемых.

Доля запасов промышленных категорий железных руд составляет $59 \%$ от общероссийских, мела $-64 \%$, гипса $-57 \%$, доломитов - 45\%, тугоплавких глин - $41 \%$, формовочных материалов - $31 \%$, цементного сырья - $27 \%$, огнеупорных глин - $18 \%$, стекольного сырья 26\%. Имеются запасы песка, гравия, щебня, камня.

Роль Центрального федерального округа наиболее велика в производстве электроэнергии (22,1\% общероссийских объемов), проката черных металлов $(19,2 \%)$, выплавке стали $(17 \%)$, производстве цельномолочной продукции $(35 \%)$, хлебобулочных изделий 
$(29,1 \%)$, водки и ликероводочных изделий $(37,9 \%)$ различных видов тканей $(30 \%)$, отдельных видов продукции химической и нефтехимической промышленности. Лидирующие отрасли пищевой промышленности - caхарная, мукомольно-крупяная, маслобойная, мясная, спиртовая, кондитерская, плодоовощная и табачно-махорочная.

Производительность труда в целом по Центральному федеральному округу в 1,4 раза выше, чем в России, в 2,2 раза выше среднемировой, и на 20\% ниже средней по Европейскому Союзу. Такое соотношение достигается очень высокими показателями г. Москвы (в 2,9 раза выше среднероссийского значения).

Однако, наряду с этим нарастает проблема обращения с отходами производства и потребления и ухудшением экологической обстановки в регионе.

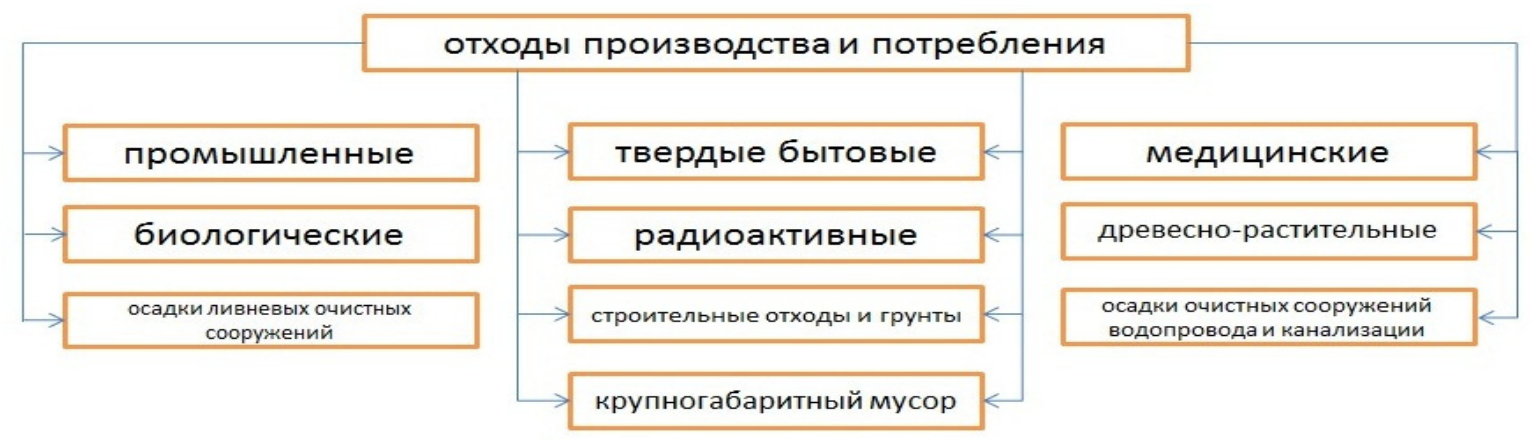

Рисунок 1 - Структура отходов производства и потребления

Жилищно-коммунальные службы наибольшей проблемой считают твердые бытовые отходы (ТБО), т.к. образуются они повсеместно и представляют собой смесь разнообразного фракционного состава, что затрудняет их сбор, обезвреживание и утилизацию.

Например, только на территории г. Москвы образуется несколько миллионов тонн

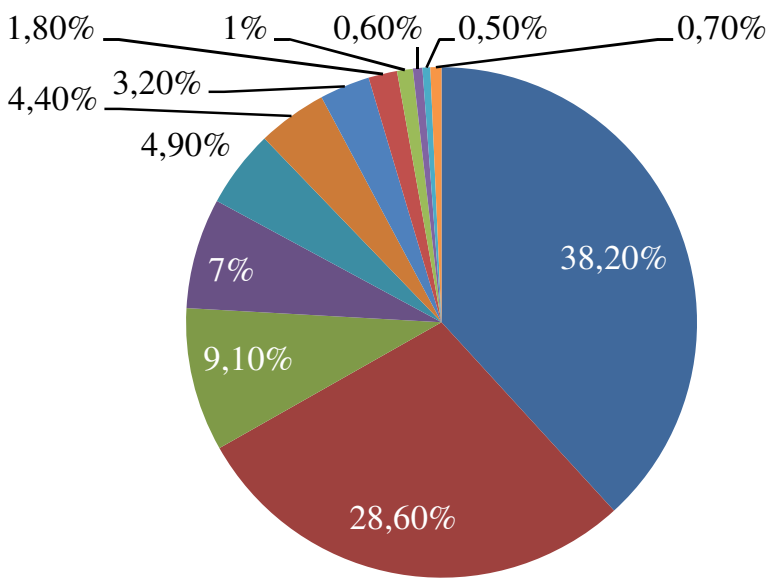

отходов, в том числе 3 млн. тонн твердых бытовых отходов и практически все они подвергаются захоронению на территории Московской области. Утвержденная норма накопления бытовых отходов на 1 человека в год составляет 1 куб. м или 250 кг, на рисунке представлена морфологическая структура указанного объема отходов.

Рисунок 2 - Структура образования отходов в Москве, утвержденная нормами накопления бытовых отходов на 1 человека в год [1]

Согласно официальным данным - средний ежегодный темп прироста отходов производства и потребления составляет 14\%. Ежегодный прирост объема ТБО в регионах ЦФО по оценкам «Гринпис России» и Росстата со-
- Бумага, картон

- Пищевые отходы

- Дерево, листья

- Текстиль

- Кожа,резина

- Полимерные материалы

- Кости

- Черный металл

- Цветной металл

- Стекло

- Керамика, камни

- Отсев 


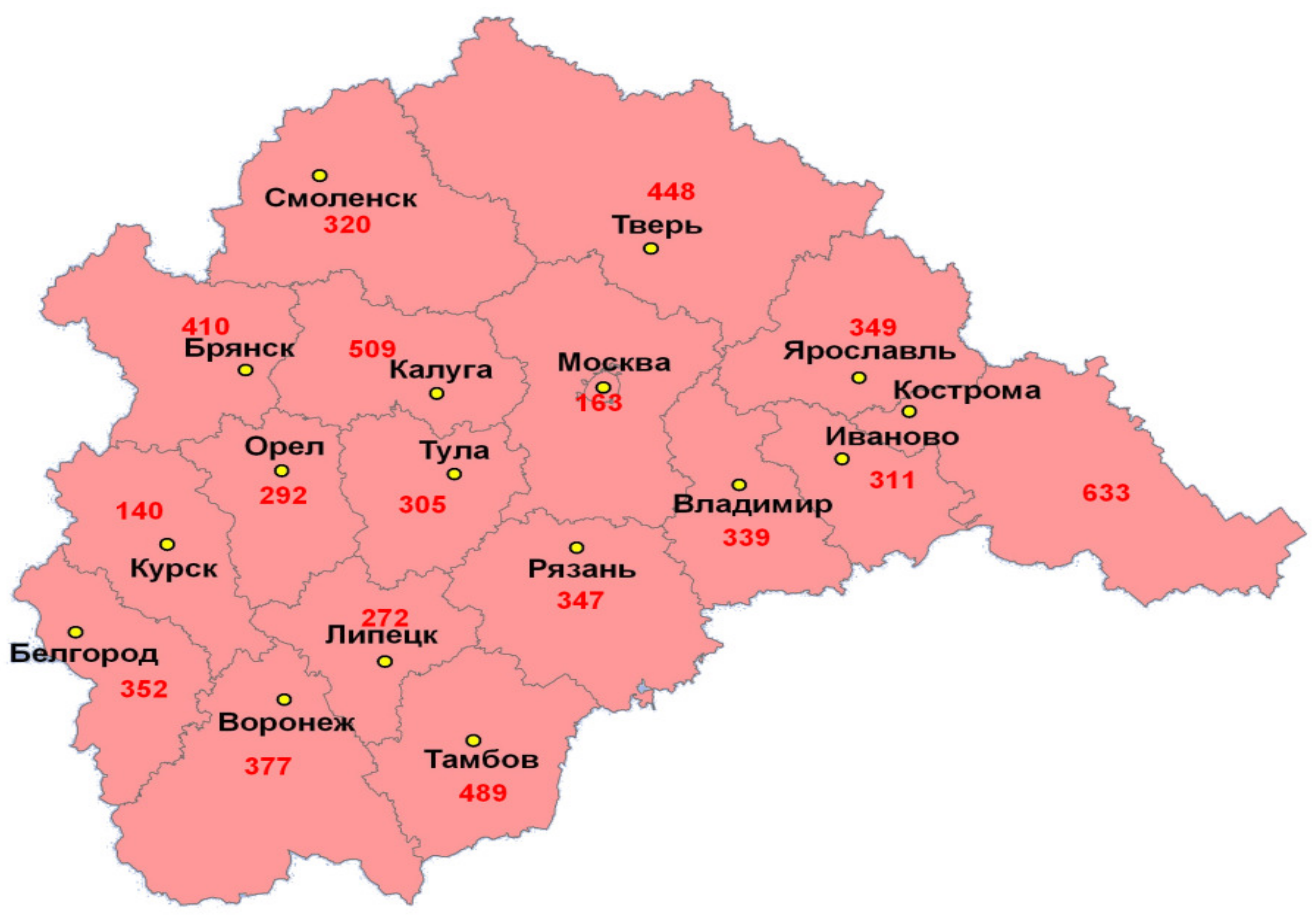

Рисунок 3 - Количество мусора (кг/год) на душу населения областных городов ЦФО по данным за 2008 г. Источник: Росстат.

Экономические механизмы охраны окружающей среды получили свою реализацию в Российской Федерации в виде платы за выбросы, сбросы загрязняющих веществ в окружающую среду и размещение отходов. Размеры платы за негативное воздействие и порядок ее определения регламентировались постановлением Совета Министров РСФСР от 9 января 1991 г. № 13 «Об утверждении на 1991 год нормативов платы за выбросы загрязняющих веществ в природную среду и порядка их применения».

Позднее природоохранными органами был подготовлен документ, который утверждался постановлением Правительства Российской Федерации от 28 августа 1992 г. №632, где также предусматривался экономический механизм управления отходами и внесение определенной платы за их размещение в экологические фонды федерального, регионального и местного уровней.

Дифференциация платы должна происходить на уровне каждого субъекта Федерации путем введения в расчеты соответствующих коэффициентов (ранее они назывались коэффициентами экологической ситуации и экологической значимости). Практика природопользования последних двадцати лет показа- ла, что подобный методологический подход содержит ряд недоработок и может быть модифицирован в соответствии с требованиями концепции «устойчивого развития».

По мнению автора в данном случае целесообразно использовать нижеприведенную формулу для оценки степени экологической безопасности оцениваемой территории области, введя туда новые дифференцированные коэффициенты региональной геоэкологической напряженности, в которые были бы заложены социальные и экологические показатели:

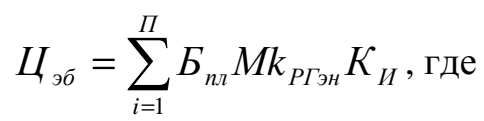

$b_{n л}-$ базовый норматив платы за загрязнение окружающей среды, руб.т/год; $M$ - реальная масса загрязнителей, попадающих на территорию размещения отходов; т/год; $K_{И}$ - коэффициент индексации платы, ежегодно утверждаемый Минприроды России по согласованию с Минфином России и Минэкономразвития России; $\Pi$ - количество видов

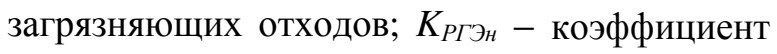
региональной геоэкологической напряженности, рассчитываемый по формуле: 


$$
k_{\text {РГЭн }}=\frac{\rho_{\text {рег. }}}{\rho_{Ц ф О}} \cdot k_{\ni \phi}, \text { где }
$$

$\rho$ - число жителей на 1 кв. км по региону; $\rho_{\text {рег }}$ - число жителей на 1 кв. км рассматриваемого региона; $k_{э ф}-$ коэффициент, учитывающий экологические факторы (состояние почвы) по территориям экономических ре- гионов РФ согласно Постановлению Правительства РФ от 12.06.2003 №344.

На рис. 4 представлены данные по коэффициенту региональной геоэкологической напряженности для регионов ЦФО, за исключением города Москвы, для которого коэффициент будет завышен из-за большого притока трудовых мигрантов (численность населения г. Москвы - 11552 тыс. человек).

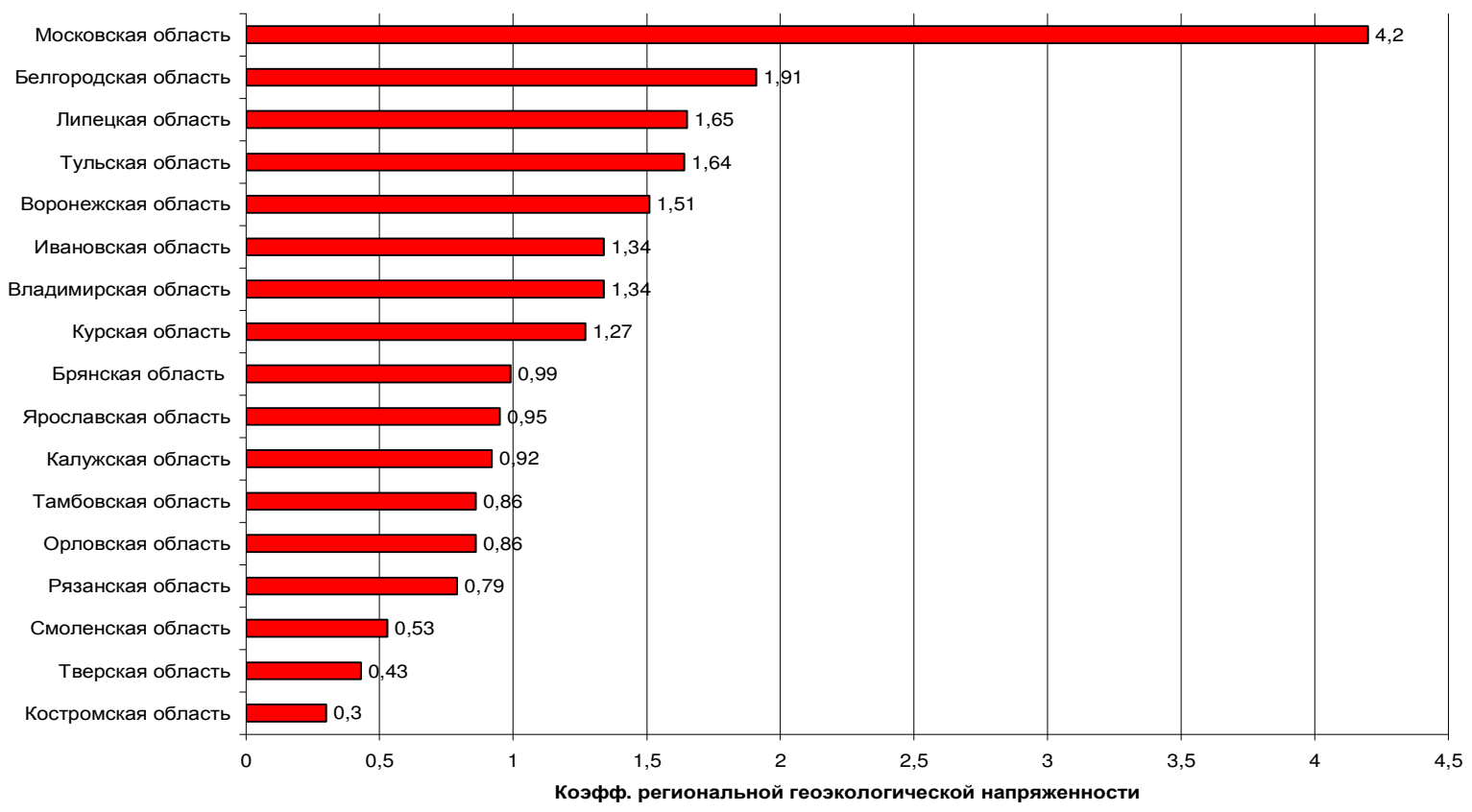

Рисунок 4 - Расчет коэффициента региональной геоэкологической напряженности для регионов Центрального федерального округа Российской Федерации

Кроме того, необходимо учитывать степень вторичного использования материальных и природных ресурсов (или процент использования отходов) на территории области. Субъектам предпринимательской деятельности необходимо предоставить право коррекции размеров платежей за загрязнение окружающей среды промышленными отходами в случаях их повторного использования в любых отраслях: капитальном строительстве (шлаки), металлургии (металлолом), в производстве бумаги (макулатура) и т.д. Подобный инновационный методологический подход имеет пионерный характер и находится на стадии диссертационного исследования.

\section{БИБЛИОГРАФИЯ}

Бурейко Е.Н. «Экология городов. Отходы производства и потребления» [Электронный ресурс]. - Режим доступа: http://www.portal-slovo.ru (дата обращения 02.08.2012).

Воробьев А.Е. Основы природопользования: экологические, экономические и правовые аспекты. Учебное пособие / А.Е.Воробьев и др. /Под ред. проф.
В.В.Дьяченко. - Ростов-на-Дону: Феникс, 2006. 544 с.

Кураев С.Н., Мамин Р.Г. Экологическая конверсия и устойчивое развитие Российской Федерации. М.: ТИССО, 2003. 88c.

Эффективность государственного управления. Пер. с англ. Под ред. С.А. Батчикова и др. М.: Консалбанкир, 1998. 842с. 